DOI: https://doi.org/10.15688/lc.jvolsu.2017.2.1

UDC 349.6:659.3

LBC 67.407 .03

\title{
CURRENT LEGAL ISSUES OF ACCESS TO ENVIRONMENTAL INFORMATION THROUGH INFORMATION AND TELECOMMUNICATION NETWORKS
}

\author{
Nazir T. Razgeldeev \\ Saratov State University, Saratov, Russian Federation \\ Valeriy Yu. Krepitsa \\ Saratov Branch JSC “ER-Telecom Holding”, Saratov, Russian Federation
}

Introduction: the availability of information in the field of environmental protection is one of the tools of realization by the subjects of environmental and natural resource relations of their legal status. In this connection, the research of the issues of legal regulation of the citizens' access to this information both by the environmental legislation and the legislation on information, allows identifying the problems of the legislative regulation of the specified relations, as well as the law enforcement. The purpose of the article: the authors attempt to identify the regulatory legal acts in the sphere of environmental protection and in the sphere of information, which regulate the relations in the sphere of ecological education and environmental information, and to analyze the impact of the enforcement of these norms on the behavior of participants of information relations in the sphere of environmental protection. Methods: in the article the methods of comparative and system analysis are used. Results: the article reviewed the topical problems of enforcement of the provisions of Federal law No. 7-FZ of January 10, 2002 "On Environmental Protection" on environmental education and ecological knowledge in conjunction with the provisions of the information legislation of the Russian Federation; assessed the impact of the practice in the application of norms on the responsibilities and duties of communications service providers and the Internet access providers on the information availability in the field of environmental protection; identified the conflicts between the norms of legislation in the sphere of environmental protection and the provisions of the information legislation; - covered the risks emerging during the implementation of the provisions of Federal law No. 436-FZ of December 29, 2010 "On Protecting Children from Information Harmful to their Health and Development" for $\therefore$ the subjects of the educational relations in the sphere of environmental protection. Conclusions: the relations in the sphere of environmental education and environmental information are regulated by both the statutory regulations of environmental protection and the legislation in the sphere of information, each of which has its own subject of regulation, the subject-object structure, and the principles of legal regulation. The encumbrance of the legal status of participants of these relationships by additional responsibilities may have a significant stagnating effect on the regulated relationships, in this case, the relations in the sphere of ecological education and information on environmental protection through the information and telecommunications networks. We believe that the development of such acts must be accompanied by a calculation of costs that would be borne by participants of these relations, and by the prognosis of the impact of changes on the subjects' behavior.

Key words: ecological education, ecological knowledge, communications service providers, Internet access providers, environmental legislation. 
УДК 349.6:659.3

ББК 67.407 .03

\title{
АКТУАЛЬНЫЕ ПРАВОВЫЕ ВОПРОСЫ ОБЕСПЕЧЕНИЯ ДОСТУПА К ЭКОЛОГИЧЕСКОЙ ИНФОРМАЦИИ ПОСРЕДСТВОМ ИНФОРМАЦИОННО-ТЕЛЕКОММУНИКАЦИОННЫХ СЕТЕЙ
}

\author{
Назир Тагирович Разгельдеев \\ Саратовский национальный исследовательский государственный университет им. Н.Г. Чернышевского, \\ г. Саратов, Российская Федерация
}

Валерий Юрьевич Крепица

Филиал в г. Саратов АО «ЭР-Телеком Холдинг», г. Саратов, Российская Федерация

\begin{abstract}
Введение: доступность информации в сфере охраны окружающей среды является одним из инструментов реализации субъектами природоохранных и природоресурсных отношений своего правового статуса. В связи с этим исследование вопросов правового регулирования доступа граждан к указанной информации нормами как природоохранного законодательства, так и законодательства об информации позволяет выявить проблемы законодательного регулирования указанных отношений, а также правоприменения. Цель: в статье предпринята попытка выявить нормативные правовые акты в сфере охраны окружающей среды и в сфере информации, регулирующие отношения в сфере экологического образования и экологической информации, провести анализ влияния правоприменения указанных норм на поведение участников информационных отношений в сфере охраны окружающей среды. Методы: при написании данной статьи использованы методы сравнительного и системного анализа. Результаты: в настоящей статье дан анализ актуальных проблем правоприменения норм Федерального закона от 10 января 2002 г. № 7-Ф3 «Об охране окружающей среды» в экологическом образовании и экологических знаниях во взаимосвязи с положениями информационного законодательства Российской Федерации; дана оценка влиянию практики применения норм об ответственности и обязанностях операторов связи и организаторов доступа в сеть Интернет на доступность информации в области охраны окружающей среды, выявлены коллизии между нормами законодательства в сфере охраны окружающей среды и положениями информационного законодательства, освещены риски, складывающиеся при реализации положений Федерального закона от 29 декабря 2010 г. № 436-Ф3 «О защите детей от информации, причиняющей вред их здоровью и развитию» для субъектов образовательных отношений в сфере охраны окружающей среды. Выводы: отношения в сфере экологического образования и экологической информации регулируются нормами как законодательства об охране окружающей среды, так и законодательства в сфере информации, каждое из которых имеет свой предмет регулирования, субъектно-объектный состав, принципы правового регулирования. Обременение правового статуса участников указанных отношений дополнительными обязанностями может оказать существенное стагнирующее воздействие на регулируемые отношения, в данном случае на отношения в сфере экологического образования и получения информации об охране окружающей среды посредством информационно-телекоммуникационных сетей. Полагаем, что разработка подобных актов должна сопровождаться расчетом затрат, которые будут нести участники указанных отношений, а также прогнозом влияния изменений на поведение субъектов.
\end{abstract}

Ключевые слова: экологическое образование, экологические знания, операторы связи, организаторы доступа в сеть Интернет, природоохранное законодательство.

\section{Введение}

2017 год запомнится нам не только в качестве столетней годовщины двух революций в России. Он является водоразделом, который покажет, какие тенденции в сфере правового регулирования информационных отношений в сфере охраны окружающей среды при- обретут доминирующее значение - тенденции открытости и доступности информации в сфере охраны окружающей среды и природопользования или же стремление к обременению правового статуса участников информационных отношений дополнительными обязанностями. К такому выводу позволяют прийти два события, свидетелями которых мы являем- 
ся. С одной стороны, 2017-й объявлен Годом экологии, с другой - это год, когда операторы связи должны запланировать затраты на реализацию с 20 июля 2018 г. ресурсозатратных положений (для операторов, а в случае их реализации, то, есть основания полагать, и для всех абонентов и пользователей услугами доступа в сеть Интернет) одного из законов так называемого пакета законов Яровой - Федерального закона от 6 июля 2016 г. № 374Ф3 «О внесении изменений в Федеральный закон "О противодействии терроризму” и отдельные законодательные акты Российской Федерации в части установления дополнительных мер противодействия терроризму и обеспечения общественной безопасности» [8].

\section{Проти воречия}

\section{в правовом регулировании}

\section{информационных отношений}

в сфере охраны

\section{окружающей среды в 2016-2017 гг.}

Таким образом, с одной стороны мы имеем место с декларируемым на уровне указа Президента РФ и распоряжения Правительства РФ приоритетом экологической безопасности, доступности экологической информации, всеобщности экологического образования и с подписанным Президентом РФ законом, отягчающим статус операторов связи и возлагающим на них дополнительные, более чем затратные обязанности, с другой.

Так, Указом Президента РФ от 5 января 2016 г. № 7 «О проведении в Российской Федерации Года экологии» поручено в 2017 г. провести Год экологии [4]. В разработанном во исполнение данного указа Плане основных мероприятий по проведению в 2017 г. в Российской Федерации Года экологии вопросам экологического просвещения и доступности экологической информации уделено весьма значительное место [3]. Не только раздел 8 Плана полностью посвящен вопросам экологического просвещения, но и иные разделы, предусматривающие регулирование отдельных направлений охраны окружающий среды и природопользования (нормирование в области охраны окружающей среды, правовую охрану вод, лесов), предусматривают информационную компоненту. Например, раздел 1
«Отходы» содержит подраздел «Формирование информационной системы взаимодействия общества и государственных органов по выявлению, пресечению и ликвидации несанкционированных мест размещения отходов». Среди соисполнителей распоряжения указан и федеральный орган исполнительной власти, осуществляющий функции по выработке и реализации государственной политики и нормативно-правовому регулированию в сфере информационных технологий,--Министерство связи и массовых коммуникаций Российской Федерации.

В то же время в соответствии с абз. 4 подп. «а» п. 2 ст. 13 Федерального закона № 374-Ф3 с 1 июля 2018 г. на операторов связи возложена обязанность хранить в течение шести месяцев текстовые сообщения, голосовую информацию, изображения, звуки, видео, иные сообщения пользователей услугами связи с момента окончания их приема, передачи, доставки и (или) обработки [8].

Стоимость затрат операторов связи на реализацию этой части указанного закона, по расчетам специалистов, определена в размере от 5 до 10 трлн рублей [2]. Логично предположить, что эти затраты операторы связи постараются компенсировать путем повышения стоимости услуг связи, что негативно скажется, в том числе, и на доступности информации в сфере охраны окружающей среды, распространяемой посредством информационно-телекоммуникационных сетей.

\section{Анализ тенденций в регулировании правового статуса участников рассматриваемых отношений}

Такой двойственный подход к регулированию информационных отношений в сфере охраны окружающей среды складывается на территории Российской Федерации уже на протяжении длительного времени. С одной стороны, имеется тенденция к нормативному закреплению положений о доступности экологических знаний, в том числе посредством использования информационно-телекоммуникационных сетей. При этом имеет место и установление дополнительных затратных обязанностей для владельцев и операторов связи, в том числе экономических. На наш взгляд, 
от этого надо отказаться: во-первых, это невыполнимо в период экономического кризиса, во-вторых, нецелесообразно и необоснованно возложение затратных обязанностей для операторов и недопустимо через это установление ограничений для пользователей сети Интернет в получении информации о состоянии объектов охраны окружающей среды. Нельзя согласиться и с усилением правовой ответственности для всех участников отношений экологического образования, а также организаций, распространяющих в интернет-сетях экологические знания (учреждения образования, музеи, библиотеки, учреждения культуры). Правоприменительная практика в сфере информационно-телекоммуникационных способов получения экологической информации и экологических знаний, как и нормативное правовое регулирование в указанной сфере отличаются противоречивым характером, и потому их следует привести в соответствие с требованиями природоохранного законодательства.

Главенствующее место экологического образования как инструмента формирования экологической культуры и профессиональной подготовки специалистов в области охраны окружающей среды закреплено в Федеральном законе от 10 января 2002 г. № 7-Ф3 «Об охране окружающей среды» в разделе «Основы формирования экологической культуры» [12], устанавливающем создание системы всеобщего и комплексного экологического образования, а также распространение экологических знаний, в том числе через средства массовой информации, музеи, библиотеки, учреждения культуры, природоохранные учреждения, организации спорта и туризма.

Учитывая всеохватывающую роль современных средств связи и телекоммуникаций, существенное значение в качестве средства и источника получения и обмена информацией в сфере охраны окружающей среды и природопользования приобретает информационно-телекоммуникационная сеть Интернет. И операторы связи, не являясь, собственно, субъектами природоохранных и природоресурсных отношений, оказывают влияние на данные общественные отношения.

Так, в качестве правовых механизмов, обеспечивающих права граждан в сфере ох- раны окружающей среды, обратим внимание на нормы Федерального закона от 27 июля 2006 г. № 149-Ф3 «Об информации, информационных технологиях и о защите информации» [10], устанавливающего запрет на ограничение доступа к информации о состоянии окружающей среды; информации о деятельности государственных органов и органов местного самоуправления; информации, накапливаемой в открытых фондах библиотек, музеев и архивов, а также в государственных, муниципальных и иных информационных системах, созданных или предназначенных для обеспечения граждан (физических лиц) и организаций такой информацией.

К положительным моментам, создающим правовую базу для доступа граждан к природоохранной информации, можно отнести и нормы Федерального закона от 9 февраля 2009 г. № 8-Ф3 «Об обеспечении доступа к информации о деятельности государственных органов и органов местного самоуправления» [11], закрепляющего обязанность органов государственной власти и органов местного самоуправления создавать официальные сайты в информационно-телекоммуникационной сети Интернет, содержащие информацию о деятельности государственного органа или органа местного самоуправления.

Более того, в целях реализации норм вышеприведенного закона изданы и подзаконные нормативные акты, устанавливающие требования к распространению органами государственной власти информации о своей деятельности, в том числе и в сфере охраны окружающей среды и обеспечения экологической, промышленной, радиационной, санитарноэпидемиологической безопасности населения.

Так, в качестве примера можно назвать Указ Президента РФ от 7 мая 2012 г. № 601 «Об основных направлениях совершенствования системы государственного управления» [5], предусматривающий обязанность создания системы раскрытия информации о разрабатываемых проектах нормативных правовых актов, результатах их общественного обсуждения, в том числе путем создания единого ресурса в сети Интернет.

В результате применения указанных нормативных правовых актов была сформирована система интернет-сайтов органов государ- 
ственной власти и органов местного самоуправления, содержащая информацию и знания в сфере охраны окружающей среды и обеспечения безопасности [6;7].

Так, создан и функционирует интернетсайт Федеральной службы по экологическому, технологическому и атомному надзору, содержащий информацию о перечне территориальных органов Ростехнадзора, подведомственных организаций Ростехнадзора, планах проведения проверок юридических лиц и индивидуальных предпринимателей; реестры лицензий на конкретные виды деятельности, лицензирование которых осуществляется Ростехнадзором; сведения об осуществлении Ростехнадзором государственного контроля (надзора), нормативные правовые акты в данной сфере.

Аналогичным образом действует интернет-сайт Федеральной службы по надзору в сфере защиты прав потребителей и благополучия человека.

Среди органов государственной власти в области охраны окружающей среды можно назвать министерство природных ресурсов и экологии Саратовской области, создавшее свой официальный интернет-сайт в сети Интернет. Также интернет-сайтами обладают и общественные экологические организации.

Таким образом, граждане и общественные организации посредством информационно-телекоммуникационных сетей могут получить доступ к информации о деятельности органов государственного управления в сфере охраны окружающей среды, отчетам об их деятельности, судебной практике по вопросам охраны окружающей среды, сформировать представление о субъектах общественных отношений в сфере охраны окружающей среды и природопользования.

В то же время обратные тенденции в области применения законодательства о связи, а также новеллы, вносимые в законодательство о связи, создают угрозу для субъектов экологического образования (образовательных учреждений, музеев, библиотек, учреждений культуры), организующих доступ в сеть Интернет для общающихся и посетителей, в том числе с целью получения экологической информации и экологических знаний.
Так, нормативно закреплены обязанности по ограничению доступа несовершеннолетних к сведениям, распространяемым в информационно-телекоммуникационных сетях и представляющим угрозу их развитию. Данные требования предусмотрены в Федеральном законе от 29 декабря 2010 г. № 436-Ф3 «О защите детей от информации, причиняющей вред их здоровью и развитию» [9].

Указанным федеральным законом вполне обоснованно установлен запрет на распространение среди несовершеннолетних информации: побуждающей детей к совершению действий, представляющих угрозу их жизни и (или) здоровью, в том числе к причинению вреда своему здоровью, самоубийству; способной вызвать у детей желание употребить наркотические средства, психотропные и (или) одурманивающие вещества, табачные изделия, алкогольную и спиртосодержащую продукцию, принять участие в азартных играх, заниматься проституцией, бродяжничеством или попрошайничеством, и других видов информации.

К организациям, на которые возложена реализация мер по ограничению доступа несовершеннолетних к подобной информации и которые могут быть привлечены к юридической ответственности, относятся учреждения образования и культуры, музеи, библиотеки, использующие фиксированный доступ в сеть Интернет, а также доступ к сети Интернет по технологии wi-fi.

Так, в соответствии с абз. 1 ст. 14 указанного закона [9] доступ к информации, распространяемой посредством информационно-телекоммуникационных сетей, в том числе сети Интернет, в местах, доступных для детей, предоставляется лицом, организующим доступ к сети Интернет в таких местах (за исключением операторов связи, осуществляющих свои услуги на основании договоров об оказании услуг связи, заключенных в письменной форме), другим лицам при условии применения административных и организационных мер, технических, программно-аппаратных средств защиты детей от информации, причиняющей вред их здоровью и (или) развитию.

Можно заключить, что учреждения образования, подписавшие гражданско-правовой 
договор на оказание телематических услуг связи (услуг доступа в сеть Интернет) и обеспечивающие возможность доступа для лиц, не достигших восемнадцатилетнего возраста, в сеть Интернет, обязаны обеспечить функционирование комплекса административных и организационных мер, технических, программно-аппаратных средств защиты несовершеннолетних от негативной информации. При том, что реестра запрещенных к посещению несовершеннолетними лицами сайтов в сети Интернет данный нормативный правовой акт не содержит, то при выполнении учреждениями образования, музеями, библиотеками обязанностей, возложенных на них указанным законом, у субъектов образовательных отношений возникают две возможные линии поведения: отказаться от пользования телематическими услугами связи либо подвергаться риску привлечения к административной ответственности по признакам правонарушения, предусмотренного ч. 2 ст. 6.17 КоАП РФ [1].

Обращаем внимание и на то, что возможность получения обучаемыми лицами информации об охране окружающей среды и природопользования посредством пользования телематическими услугами связи не служит приоритетом в ходе осуществления проверок контрольно-надзорными органами исполнения мер по защите детей от негативной информации [2] в результате чего на протяжении 2015-2016 гг. на территории Российской Федерации многие подобные учреждения были привлечены судом к административной ответственности.

Возникает резонный вопрос: как можно в ходе руководства организацией - субъектом образовательных отношений в сфере охраны окружающей среды предоставлять возможность несовершеннолетним получать экологическую информацию посредством сети Интернет и минимизировать риск привлечения к административной ответственности по ч. 2 ст. 6.17 КоАП РФ?

Субъектами исследуемых отношений предлагаются различные способы. Так, установление контентного фильтра, предлагаемое рядом операторов связи, не позволяет в достаточной мере обеспечить соблюдение образовательным учреждением норм ст. 14 Федерального закона № 436-Ф3 [9] в связи с сохранением возможности посещения несовершеннолетними интернет-сайтов, которые могут содержать негативную для них информацию.

Рособразованием в 2008 г. был предложен способ ограничения доступа к негативной информации учащихся образовательных учреждений путем использования серверов. Но имеет место недостаточное понимание реализации указанного механизма со стороны интернет-провайдеров и учреждений образования.

\section{Выводы}

Таким образом, можно прийти к следующим заключениям. Отношения в сфере информационного обеспечения доступности информации в сфере охраны окружающей среды регулируются как нормами законодательства об охране окружающей среды, так и законодательством в сфере информации, каждое из которых имеет свой предмет регулирования, субъектно-объектный состав, принципы правового регулирования. И какие-либо изменения в нормативных правовых актах природоохранного права или в законодательстве о связи могут оказать существенное воздействие на регулируемые отношения, в данном случае на отношения в сфере экологического образования и получения информации об охране окружающей среды посредством информационно-телекоммуникационных сетей. Полагаем, что разработка подобных актов должна сопровождаться расчетом затрат, которые будут нести участники указанных отношений, а также прогнозом влияния изменений на поведение субъектов.

Можно, конечно, предположить, что при внесении в Федеральное собрание Российской Федерации и принятии Федерального закона № 374-Ф3 [8] разработчики преследовали цель обеспечения безопасности общества и государства либо готовились к президентским выборам 2018 г., а последствия для отрасли связи и опосредованно для отношений по экологическому образованию в виде дополнительных затрат как для операторов, так и для абонентов будут минимизированы посредством внесения изменений в законодательство о связи касательно снижения объемов хранения информации операторами связи, предусмотренных дан- 
ным законом. А пока подобные изменения не внесены, правовое регулирование отношений в сфере информационно-телекоммуникационного обеспечения экологического образования и поиска экологической информации напоминает «Вавилонскую башню» Питера Брейгеля, с одной стороны находящуюся в строительных лесах и разрушаемую с другой. Но все-таки хочется надеяться, что консенсус между интересами государственной безопасности и правами участников информационных отношений, в том числе и в сфере охраны окружающей среды, будет достигнут.

\section{СПИСОК ЛИТЕРАТУРЫ}

1. Кодекс Российской Федерации об административных правонарушениях : [текст с изм. и доп. на 1 сент. 2016 г.]. - М. : Эксмо, 2016. - 464 с.

2. «Пакет Яровой» предлагают уценить. Электрон. текстовые дан. - Режим доступа: http:// www.kommersant.ru/doc/3199479. - Загл. с экрана.

3. Распоряжение Правительства РФ от 2 июня 2016 г. № 1082-p. - Электрон. текстовые дан. - Режим доступа: http:/giod.consultant.ru/documents/ 3710280. - Загл. с экрана.

4. Указ Президента РФ «О проведении в Российской Федерации Года экологии» от 5 янв. 2016 г. № 7. - Электрон. текстовые дан. - Режим доступа: http://www.garant.ru/products/ipo/prime/doc/ 71196604/. - Загл. с экрана.

5. Указ Президента РФ «Об основных направлениях совершенствования системы государственного управления» от 7 мая 2012 г. № 601 // Собрание законодательства РФ. - 2012. - 7 мая (№ 19). Ст. 2338.

6. Федеральная служба по надзору в сфере защиты прав потребителей и благополучия человека. - Электрон. текстовые дан. - Режим доступа: http://rospotrebnadzor.ru/. - Загл. с экрана.

7. Федеральная служба по экологическому, технологическому и атомному надзору. - Электрон. текстовые дан. - Режим доступа: http:// www.gosnadzor.ru/. - Загл. с экрана.

8. Федеральный закон «О внесении изменений в Федеральный закон “О противодействии терроризму” и отдельные законодательные акты Российской Федерации в части установления дополнительных мер противодействия терроризму и обеспечения общественной безопасности» от 6 июля 2016 г. № 374-Ф3 // Российская газета. 2016. - 8 июля (№ 149).

9. Федеральный закон «О защите детей от информации, причиняющей вред их здоровью и раз- витию» от 29 дек. 2010 г. № 436-Ф3 // Российская газета. - 2010. - 31 дек. (№ 297).

10. Федеральный закон «Об информации, информационных технологиях и о защите информации» от 27 июля 2006 г. № 149-Ф3 // Российская газета. - 2006. - 29 июля (№ 165).

11. Федеральный закон «Об обеспечении доступа к информации о деятельности государственных органов и органов местного самоуправления» от 9 февр. 2009 г. № 8-Ф3 // Собрание законодательства РФ. - 2009. - 16 февр. - № 7. - Ст. 776.

12. Федеральный закон «Об охране окружающей среды» от 10 янв. 2002 г. № 7-Ф3 // Собрание законодательства РФ. - 2002. - 14 янв. - № 2. - Ст. 133.

\section{REFERENCES}

1. Kodeks Rossiyskoy Federatsii ob administrativnykh pravonarusheniyakh: tekst s izm. $i$ dop. na 1 sent. 2016 g. [Code of the Russian Federation on Administrative Offenses. Text with amendments and additions as of September 1, 2016]. Moscow, Eksmo Publ., 2016. 464 p.

2. "Paket Yarovoy» predlagayut utsenit [It's Proposed to Discount "Yarovaya's Package"]. URL: http://www.kommersant.ru/doc/3199479.

3. Rasporyazhenie Pravitelstva RF ot 2 iyunya 2016 g. № 1082-r [The Decree of the Government of the Russian Federation of June 2, 2016 no. 1082-r]. Available at: http://giod.consultant.ru/documents/ 3710280.

4. Ukaz Prezidenta $R F \ll O$ provedenii $v$ Rossiyskoy Federatsii Goda ekologii» ot 5 yanv. 2016 g. № 7 [The Decree of the President of the Russian Federation "On Holding a Year of Ecology in the Russian Federation" of January 5, 2016 no. 7]. URL: http://www.garant.ru/products/ipo/prime/doc/ 71196604/. (accessed March 13, 2017).

5. Ukaz Prezidenta RF «Ob osnovnykh napravleniyakh sovershenstvovaniya sistemy gosudarstvennogo upravleniya» ot 7 maya $2012 \mathrm{~g}$. № 601 [The Decree of the President of the Russian Federation "On Main Directions of Improving the System of State Management" of May 7, 2012 no. 601]. Sobranie zakonodatelstva RF [Collected Legislation of the Russian Federation], 2012, no. 19, art. 2338.

6. Federalnaya sluzhba po nadzoru $v$ sfere zashchity prav potrebiteley $i$ blagopoluchiya cheloveka [Federal Service for Surveillance on Consumer Rights Protection and Human Well-Being]. URL: http://rospotrebnadzor.ru/.

7. Federalnaya sluzhba po ekologicheskomu, tekhnologicheskomu i atomnomu nadzoru [Federal Service for Environmental, Technological and Nuclear Supervision]. URL: http://www.gosnadzor.ru/. 
8. Federalnyy zakon «O vnesenii izmeneniy v Federalnyy zakon "O protivodeystvii terrorizmu" i otdelnye zakonodatelnye akty Rossiyskoy Federatsii $\mathrm{v}$ chasti ustanovleniya dopolnitelnykh mer protivodeystviya terrorizmu i obespecheniya obshchestvennoy bezopasnosti» ot 6 iyulya $2016 \mathrm{~g}$. № 374-FZ [The Federal Law “On Amendments in the Federal Law 'On Terrorism Prevention' and Certain Legislative Acts of the Russian Federation regarding the Establishment of Additional Counter-Terrorism Measures and Ensuring Public Security"]. Rossiyskaya gazeta, 2016, no. 149 (July 8).

9. Federalnyy zakon «O zashchite detey ot informatsii, prichinyayushchey vred ikh zdorovyu i razvitiyu» ot 29 dek. 2010 g. № 436-FZ [The Federal Law "On Children's Protection from Information Harmful to Their Health and Development" of December 29, 2010 no. 436-FL]. Rossiyskaya gazeta, 2010, no. 297 (December 31).
10. Federalnyy zakon «Ob informatsii, informatsionnykh tekhnologiyakh i o zashchite informatsii» ot 27 iyulya 2006 g. № 149-FZ [The Federal Law "On Information, Information Technologies and Information Protection" of July 27, 2006 no. 149-FL]. Rossiyskaya gazeta, 2006, no. 165 (July 29).

11. Federalnyy zakon «Ob obespechenii dostupa $\mathrm{k}$ informatsii o deyatelnosti gosudarstvennykh organov i organov mestnogo samoupravleniya» ot 9 fevr. $2009 \mathrm{~g}$. № 8-FZ [The Federal Law “On Providing Access to Information on Activities of State Bodies and Bodies of Local Self-Government" of February 9, 2009 no. 8-FL]. Sobranie zakonodatelstva $R F$ [Collected Legislation of the Russian Federation], 2009, no. 7, art. 776.

12. Federalnyy zakon «Ob okhrane okruzhayushchey sredy» ot 10 yanv. 2002 g. № 7-FZ [The Federal Law “On Environmental Protection" of January 10, 2002 no. 7-FL]. Sobranie zakonodatelstva RF [Collected Legislation of the Russian Federation], 2002, no. 2, art. 133.

\section{Information about the Authors}

Nazir T. Razgeldeev, Doctor of Juridical Sciences, Professor, Head of the Department of Criminal, Ecological Law and Criminology, Saratov State University, Volskaya St., 10a, bldg. 12, office 505, 410000 Saratov, Russian Federation, razgeldeevnt@mail.ru.

Valeriy Yu. Krepitsa, Head of the Legal Department, Saratov Branch JSC "ER-Telecom Holding", Rabochaya St., 145a, 410012 Saratov, Russian Federation, krepica@mail.ru.

\section{Информация об авторах}

Назир Тагирович Разгельдеев, доктор юридических наук, профессор, заведующий кафедрой уголовного, экологического права и криминологии, Саратовский национальный исследовательский государственный университет им. Н.Г. Чернышевского, ул. Вольская, 10a, кор. 12, к. 505, 410000 г. Саратов, Российская Федерация, razgeldeevnt@mail.ru.

Валерий Юрьевич Крепица, руководитель юридического отдела, филиал в г. Саратов АО «ЭР-Телеком Холдинг», ул. Рабочая, 145a, 410012 г. Саратов, Российская Федерация, krepica@mail.ru. 